\title{
PRODUÇÃO DE CAFÉ SOMBREADO
}

\author{
Mauricio Antonio Cuzato Mancuso ${ }^{1}$, Rogério Peres Soratto ${ }^{2}$, Marcos José Perdoná ${ }^{3}$ \\ ${ }^{1}$ Doutorando em Agronomia pelo Departamento de Produção Vegetal da Faculdade de Ciências Agronômicas de Botucatu, UNESP. \\ ${ }^{2}$ Professor Assistente Doutor da Faculdade de Ciências Agronômicas de Botucatu, UNESP. ${ }^{3}$ Pesquisador da APTA - Polo Regional \\ de Ribeirão Preto-SP. E-mail: macmancuso@fca.unesp.br
}

\section{RESUMO}

Com a crescente preocupação ambiental e demanda por cafés especiais, a presente revisão teve como objetivo agregar informações a respeito dos efeitos causados pelo sombreamento sobre a cultura do café, visto que esta cultura é originária de sub-bosques africanos. Entre os efeitos abordados estão o aumento da matéria orgânica e melhoria da fauna do solo, ciclagem de nutrientes, redução dos processos erosivos no solo, contaminação ambiental, gases do efeito estufa, conservação da biodiversidade, disponibilidade luminosa, atenuação da temperatura e ventos, incidência de pragas, doenças e plantas daninhas, produção das espécies de sombreamento e, por fim, de que maneira todos esses fatores associados interferem na fenologia, produção e qualidade do café.

Palavras-chave: Coffea sp.; consorciação; cafés especiais; arborização; qualidade.

\section{SHADED COFFEE PRODUCTION}

\begin{abstract}
As concern about the environment and demand for special coffees, this review aimed to gather information about the effects of shading on the coffee crop, whereas its origin in the African's understory. Among the effects discussed are the increase in organic matter and improving of the soil fauna, nutrient cycling, decrease of soil erosion, environmental contamination, greenhouse gases, biodiversity conservation, light availability, temperature and wind mitigation, incidence of pests, plant diseases and weeds, production of the shade species and, finally, how all of these factors together have an effect on the phenology, yield and quality of coffee.
\end{abstract}

Keywords: Coffea sp.; intercropping; special coffees; arborization; quality. 


\section{1 - INTRODUÇÃO}

Condições de sombreamento em cafezais proporcionam uma maturação mais lenta dos grãos e são utilizadas em diversos países para a produção de cafés especiais. O mercado nacional, bem como o mundial, valoriza cada vez mais esses produtos, pagando mais aos produtores que se dedicam a esse tipo de produção, enquanto os cafés comercializados como "commodity" encontram grande oferta e alto estoque mundial, o que resulta em preços mais baixos.

A espécie de café Coffea arabica L. tem sua origem nas florestas dos altiplanos da Etiópia, sendo uma planta que vegeta e produz bem em áreas sombreadas de altitude e em climas úmidos. Além dessa, a espécie $C$. canephora Pierre também é originária de sub-bosques africanos, porém das regiões de menor altitude, como o Congo e Gana. Deste modo, espera-se que o manejo do café que mais se assemelhe às suas condições de origem possa proporcionar os melhores resultados. No Brasil, as variedades de café foram geneticamente selecionadas para produzir a pleno sol, entretanto o sombreamento pode ser utilizado como uma alternativa para cafés especiais.

Sabe-se que a irradiância de saturação para o café está compreendida em torno de 300 a $600 \mu \mathrm{mol} \mathrm{m} \mathrm{m}^{-2} \mathrm{~s}^{-1}$, o que permite um manejo de sombreamento nas lavouras (MOREIRA, 2003), sendo que altas intensidades luminosas saturam o aparelho fotossintético do cafeeiro, acarretando fotoinibição (NUNES et al.,1993).

Países como Etiópia, Sumatra, Nova Guiné e Timor apresentam praticamente todos os cafezais cultivados sob sombra. Na América Latina, os cafés do sul do México, norte da Nicarágua, Costa Rica, El Salvador, Peru, Panamá e Guatemala também são todos cultivados sob sombra.
O sombreamento, conduzido com a adoção de espécies para consorciamento e espaçamentos apropriados, pode proporcionar resultados satisfatórios quando comparado ao cultivo a pleno sol. Entre as vantagens do sombreamento estão: produção de internódios mais longos; redução do número de folhas, porém folhas com maior tamanho; obtenção de cafés com bebida mais suave (maturação mais lenta); aumento da capacidade produtiva do cafeeiro e redução da bienalidade de produção; menor incidência da seca de ponteiros e da cercosporiose; diminuição da desfolha; baixo ataque de bicho mineiro; atenuação das temperaturas máximas e mínimas do ambiente (menor incidência de escaldadura e geadas); renda adicional pelo aproveitamento da espécie arbórea e redução da infestação de plantas daninhas na lavoura (FERNANDES, 1986; MATIELLO, 1995).

Existem outros benefícios do sistema sombreado, abordados por Rodrigues et al. (2001), entre eles a ciclagem de nutrientes; a presença de controladores naturais de pragas $e$ doenças; melhor utilização da mão-de-obra na entressafra e atenuante da ação prejudicial dos ventos. Atualmente, também o uso de árvores no sequestro de carbono tem sido proposto como um meio para aumentar a renda de pequenos produtores de café no México (MOREIRA et al., 2003).

Por outro lado, admite-se que uma alta densidade de árvores irá resultar em significativa redução de produção. Além disso, altas incidências de broca do cafeeiro (BERGAMIN, 1946; AMARAL, 2011) e ferrugem do cafeeiro (AGRIOS, 1982) já foram relatadas em plantios de café sombreados.

Diante do exposto, objetivou-se, mediante a presente revisão, reunir informações sobre os 
efeitos do sombreamento na cultura do café e a influência em sua produção.

\section{2 - REVISÃO DE LITERATURA}

Em meados do século XIX, Lock (1888) fez algumas observações sobre os pontos positivos e negativos do sombreamento através de árvores, embasado em experimentos com manejo de cafezais no Ceilão, atual Sri Lanka. São eles:

- Faixa Climática: a necessidade de sombra varia em função do clima (o sombreamento tem especial importância em climas quentes e secos);

- Benefícios do sombreamento: aumento da longevidade das plantas de café; redução nos custos; aumento da serapilheira (consequentemente, aumento da disponibilidade de nutrientes) e venda de madeira (incremento na renda);

- Inconveniente: redução da produção de café, porém compensada pelo aumento da longevidade;

- Atributos benéficos das espécies de sombreamento: pouca ramificação, fornecimento de madeira, frutas ou outros produtos úteis, "alimentação" do subsolo, pois ocorre ciclagem de nutrientes através das folhas que caem.

Após Lock, muitas outras discussões e experimentos foram realizados na tentativa de esclarecer as reais mudanças ocasionadas pelo sombreamento de cafezais e se essas se traduzem em ganhos ou perdas na produtividade, qualidade e ao meio ambiente. Diante disso, é importante salientar alguns pontos sobre os efeitos do sombreamento no café, abordados a seguir.

Matéria orgânica, fauna do solo, fixação biológica de $\mathbf{N}$ e ciclagem de nutrientes

A utilização de espécies de sombreamento no cultivo de café proporciona um aumento da quantidade de matéria orgânica no sistema através da queda de ramos, galhos e folhas, entre outras partes das espécies vegetais. Essa manutenção de elevadas quantidades de matéria orgânica no solo pode ajudar a estabilizar a incidência de nematóides no café (Meloidogyne e Pratylenchus spp.) abaixo do nível crítico (ARAYA, 1994). Da mesma forma, a redução de estresses ambientais proporcionada pelo sombreamento aumenta a tolerância dos cafezais à infestação por nematóides (OFICAFE, 1978). Contudo, a escolha equivocada da espécie de sombreamento pode causar um efeito contrário. Por exemplo, as espécies de Inga spp. têm sido qualificadas como hospedeiros alternativos de alguns tipos de nematóides do café (ZAMORA; SOTO, 1976), porém ainda não é claro se isso aumentaria ou não a interferência dos nematóides nas plantas de café.

Lindblad e Russo (1986) encontraram níveis de redução de acetileno em um cafezal fortemente adubado e sombreado com Erythrina poeppigiana (Fabaceae), sendo semelhante aos resultados obtidos por Roskowski e van Kessel (1985) em um cafezal sem adubação, sombreado com Inga jinicuil. Já Fassbender (1987), comparando o balanço nutricional de leguminosas e não-leguminosas associadas com café para sombreamento, estimaram que $60 \mathrm{~kg} \mathrm{ha}^{-1} \mathrm{ano}^{-1}$ de nitrogênio $(\mathrm{N})$ foram fixados pela $E$. poeppigiana. Entretanto, a capacidade das espécies de sombreamento em produzirem uma quantidade elevada de material orgânico, como por exemplo, serapilheira e resíduos da poda, podem ser mais importantes que a fixação biológica de $\mathrm{N}$ devido aos efeitos positivos nas propriedades químicas e físicas do solo (BEER et al., 1998).

Em relação à ciclagem de nutrientes, Cuenca et al. (1983) constatou que as raízes de café foram infectadas com espécies de micorrizas e essas associações raízes finas-micorrizas invadiram a camada de serapilheira, resultando 
em uma micro-estratificação entre as raízes das plantas de café e as espécies de sombreamento.

Em experimentos na América Central, com cafezais sombreados por leguminosas, foi observado incrementos de matéria seca, contendo de 60 a $340 \mathrm{~kg} \mathrm{~N} \mathrm{ha}^{-1} \mathrm{ano}^{-1}$, variando de 3 a 14 t ha $^{-1}$ ano $^{-1}$ (BEER, 1988).

Babbar e Zak (1994; 1995) encontraram altas taxas de mineralização de $\mathrm{N}$ em cafezais sombreados por E. poeppigiana na Costa Rica (148 kg N ha ${ }^{-1}$ ano $^{-1}$ ), quando comparados com lavouras não sombreadas (111 kg N ha ${ }^{-1} \mathrm{ano}^{-1}$ ). Ambas as áreas foram fortemente fertilizadas com $\mathrm{N}$ mineral com doses acima de $300 \mathrm{~kg} \mathrm{~N} \mathrm{ha}^{-1}$ ano $^{-1}$. Os autores concluíram, portanto, que a ciclagem de $\mathrm{N}$ foi mais eficiente na área sombreada, porque, apesar da elevada disponibilidade de $\mathrm{N}$ mineralizado, menos $\mathrm{N}$ foi perdido por lixiviação.

\section{Erosão do solo}

O escoamento e a perda de solo são menores em plantios sombreados quando comparados àqueles conduzidos a pleno sol (LEON, 1990). Entretanto, benefícios similares podem ser obtidos com o uso de palhada (plantio direto, por exemplo), sem sombrear o ambiente. Se as espécies de sombreamento têm como finalidade o controle da erosão, a serapilheira natural e os resíduos de poda devem manter uma camada de cobertura do solo durante a estação chuvosa. Com isso, a decomposição lenta da serapilheira se torna uma vantagem (BEER et al., 1998).

\section{Contaminação ambiental, gases do efeito estufa e conservação da biodiversidade}

Os fertilizantes nitrogenados podem poluir os lençóis freáticos com nitrito e nitrato se utilizados indiscriminadamente. Partindo desse princípio, Babbar e Zak (1995) relatam que perdas anuais por lixiviação estão entre 5 a 9 kg
$\mathrm{N}$ ha ${ }^{-1}$ em sistemas sombreados e $24 \mathrm{~kg} \mathrm{~N} \mathrm{ha}^{-1}$ em cafezais a pleno sol. Assim, espécies de sombreamento têm potencial para reduzir a contaminação das águas em áreas de cafeicultura intensiva. Da mesma forma, a necessidade de reduzir a contaminação ambiental por pesticidas, os quais são extremamente usados em café, proporciona outro argumento para a manutenção de espécies de sombra (BOYCE et al., 1994).

Em estudos relacionados com o efeito estufa, Kursten e Burschel (1993) calcularam que 14 a 52 t carbono (C) ha ${ }^{-1}$ estão armazenados na biomassa da parte lenhosa das espécies de sombreamento utilizadas em cafezais. Comparando com culturas anuais, esses sistemas agroflorestais também armazenam um adicional de 10 a 50 t $\mathrm{C} \mathrm{ha}^{-1}$ na camada de serapilheira e na matéria orgânica do solo.

Há uma demanda e uma boa vontade dos consumidores em pagarem preços diferenciados por produtos agrícolas produzidos de forma sustentável ou orgânica, geralmente controlada por critérios de certificadoras (BOYCE et al., 1994). O sequestro de carbono por sistemas agroflorestais é outra opção de negócios com países desenvolvidos (DIXON, 1995), visto que muito carbono é "sequestrado" por esses sistemas através da serrapilheira, galhos e folhas de podas e da rica matéria orgânica resultante destes. Fazuoli et al. (2007) sugere que o uso da arborização seria uma das técnicas de mitigação para o possível cenário de aquecimento global e seus efeitos na cafeicultura.

Outro ponto em que diversas pesquisas internacionais estão focadas é na contribuição que os cafezais sombreados proporcionam para a manutenção da biodiversidade e como refúgio para aves migratórias (PERFECTO et al., 1996). 


\section{Disponibilidade luminosa}

Diversos autores definem que o limite máximo aceitável de sombreamento em café (planta com fisiologia C3) está entre 40 e $70 \%$ (KUMAR; TIESZEN, 1980; MUSCHLER, 1995). Entretanto, devemos considerar que as medidas de luminosidade são realizadas em folhas individuais ou plantas isoladas, as quais não representam as condições que afetam a totalidade das plantas de café em uma área a pleno sol com alta densidade populacional, onde o auto-sombreamento tem que ser considerado (BEER et al., 1998).

De acordo com DaMatta (2004), o sombreamento em cultivos arborizados de café em regiões tropicais deve cobrir cerca de $20 \%$ da superfície, sendo que 0 excesso de sombreamento pode ser prejudicial à produção dos cafeeiros. O mesmo autor relata que a utilização de espécies de sombreamento no cafezal, com consequente redução da radiação incidente, atenua o ciclo bienal da produção, além de alterar o desenvolvimento fenológico do café, proporcionando maior período de grãos maduros, permitindo mais tempo para colheita seletiva, que por sua vez pode trazer reflexos positivos na qualidade da bebida. Nesse sentido, Vaast et al. (2004), em trabalhos realizados em cafezais arborizados na Costa Rica, obtiveram melhor qualidade do produto nesses sistemas.

Com o sombreamento, as plantas aumentam sua área foliar e, com isso, aumentam a superfície fotossintetizante, promovendo um aproveitamento maior das baixas intensidades luminosas, compensando, assim, as taxas fotossintéticas por unidade de área mais baixas, que são características de folhas de sombra (TATAGIBA et al., 2010).

\section{Temperatura, ventos e umidade}

As folhas de café ficam expostas a temperaturas que excedem $40^{\circ} \mathrm{C}$ (MAESTRI; BARROS, 1977). Em cafezais do México sobre sombreamento de Inga jinicuil (205 árvores ha ${ }^{-1}$, com altura média de $14 \mathrm{~m}$ ), a média das temperaturas máximas foi reduzida em $5,4^{\circ} \mathrm{C}$ e a média das temperaturas mínimas aumentou em $1,5^{\circ} \mathrm{C}$, quando comparadas com cafezais a pleno sol (BARRADAS; FANJUL, 1986).

Pezzopane et al. (2010), trabalhando com consorcio macadâmia-café, constatou que a presença da cultura de sombreamento altera o microclima, diminuindo a incidência de radiação fotossinteticamente ativa sobre as plantas de café (Tabela 1) e causando redução na incidência do vento (Figura 1). O cultivo arborizado provocou ainda alterações no regime térmico e de umidade relativa do ar nos pontos mais próximos aos renques de macadâmia.

Tabela 1. Transmissividade da Radiação Fotossinteticamente Ativa - RFA (ou seja, relação entre a RFA sobre as plantas de café no cultivo arborizado e a RFA externa) em quatro tratamentos, em um sistema de café arborizado com macadâmia, em São Mateus (ES).

\begin{tabular}{cccc}
\hline Posição* $^{*}$ & \multicolumn{2}{c}{ Data de amostragem } & Média \\
& $13 / 09 / 2008$ & $10 / 02 / 2009$ & \\
\hline ARB 2,5 & $17,7 \pm 9,8$ & $17,0 \pm 5,68$ & $17,3 \pm 5,28$ \\
SO & & & $\mathrm{C}$ \\
ARB 5,0 & $74,1 \pm 6,87$ & $70,8 \pm 4,27$ & $\begin{array}{c}72,4 \pm 3,80 \\
\text { b }\end{array}$ \\
SO & & & $87,9 \pm 0,98$ \\
ARB 5,0 & $88,7 \pm 1,36$ & $87,2 \pm 1,52$ & a \\
NE & & & $69,6 \pm 5,62$ \\
ARB 2,5 & $78,1 \pm 6,04$ & $61,1 \pm 7,92$ & $\mathrm{~b}$ \\
NE & & - \\
Média & $64,6 \pm 7,75$ & $59,0 \pm 7,13$ & - \\
\hline $\begin{array}{l}\text { Médias não seguidas da mesma letra maiúscula na coluna e } \\
\text { da mesma letra minúscula na linha diferem entre si pelo teste t }\end{array}$ \\
(P>0,051\%). *Linha de café com distância de 2,5 ou 5,0m da \\
linha de macadâmias voltada para o sentido cardeal sudoeste \\
(SO) ou nordeste (NE). Fonte: Adaptado de Pezzopane et al. \\
(2010).
\end{tabular}



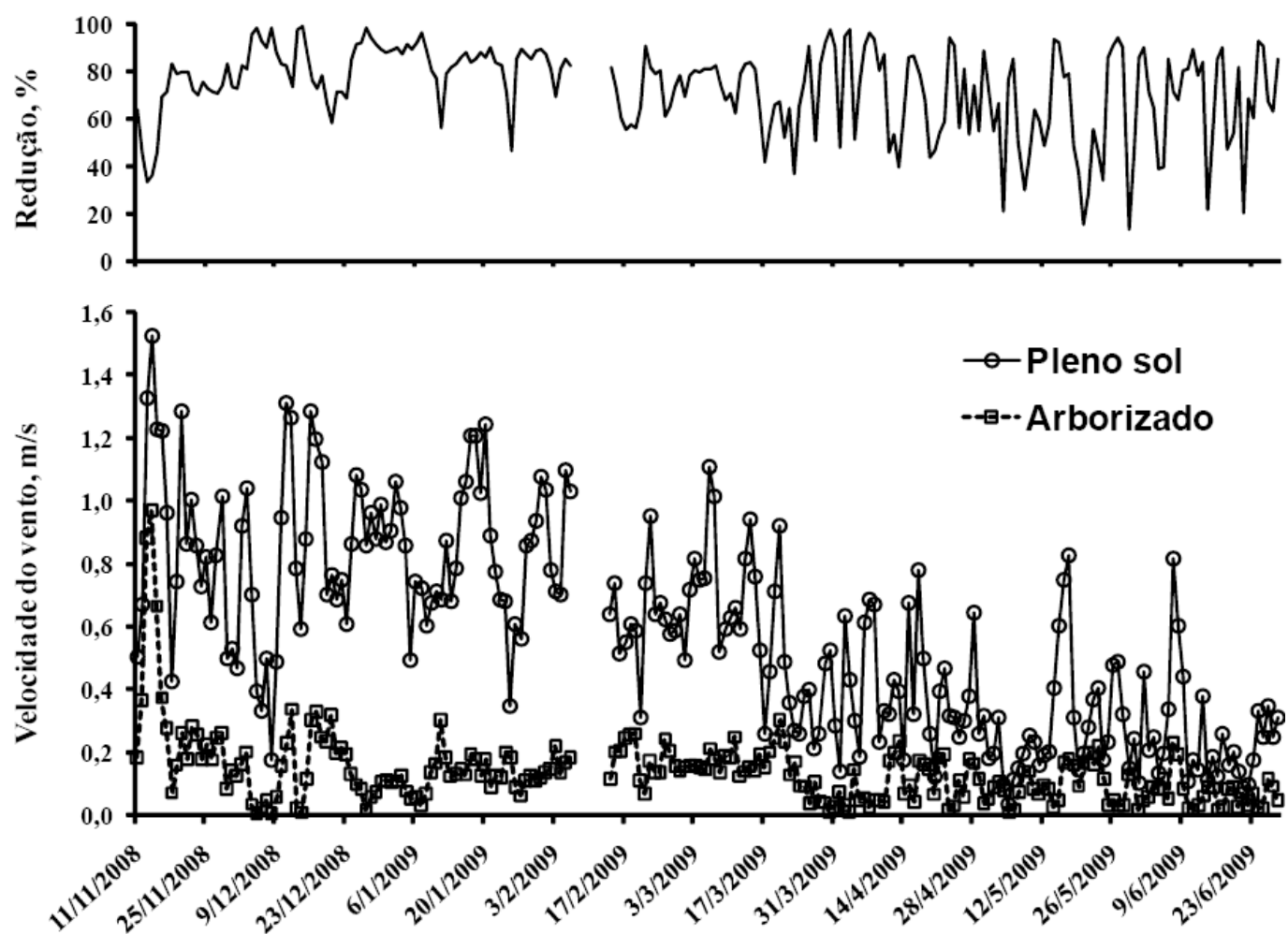

Figura 1 - Médias diárias da velocidade do vento em cultivos de café a pleno $s$ ol e arborizado com macadâmia e redução da incidência do vento no sistema arborizado em relação ao sistema a pleno sol, em São Mateus (ES). Fonte: Pezzopane et al. (2010).

\section{Pragas, doenças e plantas daninhas}

A broca do café (Hypothenemus hampei), segundo Wrigley (1988), é favorecida pelo intenso sombreamento dos cafezais. Todavia, segundo este mesmo autor, o sombreamento favorece a persistência dos agentes de controle biológico Beauveria bassiana (um fungo entomopatogênico) e Cephalonomia stephanoderis (uma vespa parasítica).

O sombreamento excessivo aumenta a incidência de importantes doenças fúngicas, como exemplo a mancha olho-de-galo ou mancha americana (Mycena citricolor) (BEER et al., 1998), principalmente em locais úmidos (próximos a rios) ou fundo de vales. No Brasil, essa doença tem considerável importância em cafezais sombreados no Ceará. Contrastando com essa ideia, danos causados por cercosporiose (Cercospora coffeicola), um fungo que pode ocasionar desfolhamento total em plantas de café, são elevados em cafezais não sombreados
(NATARAJ; SUBRAMANIAN, 1975), provavelmente pelo fato da maior suscetibilidade das plantas sob estresses hídrico ou nutricional. (WRIGLEY, 1988).

Enquanto essas generalizações são válidas para mancha olho-de-galo e cercosporiose na maioria dos casos, a correlação entre o nível de sombreamento e a incidência de ferrugem (Hemileia vastatrix) parece muito menos importante (ESKES, 1982). Esse tipo de ferrugem do café causa desfolha severa tanto em ambientes sombreados quanto em cultivos a pleno sol. Além disso, as espécies de sombreamento podem se tornar hospedeiras e, consequentemente, fonte de inóculo para diversas doenças do café.

Campanha et al. (2004), em experimento com cafezais em sistema a pleno sol e outro em sistema agroflorestal, constataram maior incidência de cercosporiose e ferrugem no segundo sistema (Tabela 2). No mesmo trabalho, 
os autores não observaram diferença de ataque do bicho-mineiro (Perileucoptera coffeella) entre os dois sistemas e justificaram o fato alegando que ambos estavam próximos e as árvores serviram como refúgio para inimigos naturais dessa praga, a qual é favorecida pela ausência de mata e também pela baixa umidade do ar.

Tabela 2. Incidência média, em \%, de bichomineiro, cercosporiose e ferrugem em plantas de café sob sistema agroflorestal (SAF) e em cultivo solteiro (SOLT), de outubro de 1998 a maio de 2000. Viçosa (MG).

\begin{tabular}{ccc}
\hline PRAGA/DOENÇA & SAF & SOLT \\
\hline Bicho-mineiro & $1,71 \pm$ & $1,22 \pm 0,18$ \\
& $0,26 \mathrm{a}$ & $\mathrm{a}$ \\
Cercosporiose & $6,92 \pm$ & $5,41 \pm 0,35$ \\
& $0,32 \mathrm{a}$ & $\mathrm{b}$ \\
Ferrugem & $8,17 \pm$ & $7,08 \pm 0,41$ \\
& $0,37 \mathrm{a}$ & $\mathrm{b}$ \\
\hline
\end{tabular}

Em cada linha, $a$ difere de $b$ pelo teste $t(p<0,05)$. Fonte: Adaptado de Campanha et al. (2004).

Teodoro et al. (2009) avaliaram a dinâmica populacional de ácaro vermelho (Oligonychus ilicis McGregor), bicho-mineiro (Leucoptera coffeella Guérin-Méneville) e broca do café em três sistemas agroflorestais com café (pouco sombreado, sombreamento intermediário e sombreamento denso em matas naturais) no Equador. Esses autores verificaram as maiores densidades de ácaro vermelho, em todos os seus estágios de desenvolvimento, no sistema pouco sombreado, ao passo que as densidades apenas da larva de bicho-mineiro e adultos da broca do café diminuíram à medida que se elevou o sombreamento do sistema.

O sombreamento pode modificar a composição de espécies daninhas, reduzindo o número das mais prejudiciais. O crescimento de plantas daninhas em cafezais é praticamente cessado sobre sombreamento homogêneo a partir de 40\% (MUSCHLER, 1997). A seleção adequada e 0 manejo de espécies de sombreamento permanentes podem reduzir consideravelmente os custos com o controle de plantas daninhas (SILVA et al., 1990). A economia resultante da ausência de plantas daninhas representa o dobro dos custos no manejo de espécies de sombreamento podadas duas vezes ao ano (ROJAS CUBERO, 1996).

\section{Fenologia, produção, qualidade de bebida e rendas extras}

Os efeitos das espécies de sombreamento na fenologia do café, particularmente na iniciação e desenvolvimento floral e de frutos, no tamanho de grãos e na qualidade de bebida são pontos que precisam ser mais bem estudados, por ser de suma importância econômica (MUSCHLER, 1995).

Com relação à fenologia da cultura do café, Cannell (1975) propôs que o menor espaçamento entre as plantas de café resultaria em um autosombreamento entre as plantas, o que poderia inibir a iniciação floral nas gemas já existentes nos ramos plagiotrópicos. Jaramillo e Valencia (1980) observaram menos flores em cafezais sombreados do que em pleno sol. Já Montoya et al. (1961 apud BEER et al., 1998), em trabalho com sombreamento artificial, constataram aumentos significativos nos números de nós por ramo de café e botões florais por nó a medida que a incidência de luz aumentava. Os mesmos autores também reportaram uma correlação positiva entre o aumento no número de nós por ramos e a produção no ano seguinte. Cannell (1975) afirmou que o componente mais importante para a produção é o número de nós (gemas) formados.

Rodrigues (2009) observou que as espécies florestais cedro australiano (Toona ciliata, var. australis) e pinus cuiabano (Parkia multijuga) reduziram o comprimento de ramo e número de nós de cafeeiros conilon, provavelmente pelo excesso de sombra proporcionada pela arquitetura das copas 
(Tabela 3). Com isso, o autor define que 0 vegetativo do café. sombreamento pode afetar o desenvolvimento

Tabela 3. Comprimento de ramo, diâmetro da copa, diâmetro de caule e altura em café em monocultivo e consorciado com três espécies florestais. Machadinho do Oeste (RO). 2007.

\begin{tabular}{cccccc}
\hline Sistemas de cultivo & $\begin{array}{c}\text { Comprimento de } \\
\text { ramo }\end{array}$ & $\begin{array}{c}\text { Número de nós } \\
\text { por ramo }\end{array}$ & $\begin{array}{c}\text { Diâmetro } \\
\text { da copa }\end{array}$ & $\begin{array}{c}\text { Diâmetro } \\
\text { do caule }\end{array}$ & $\begin{array}{c}\text { Altura da } \\
\text { planta }\end{array}$ \\
\hline Café a pleno sol & $(\mathrm{cm})$ & - & $(\mathrm{m})$ & $(\mathrm{cm})$ & $(\mathrm{m})$ \\
Café x bandara & $52,72 \mathrm{~b}$ & $11 \mathrm{a}$ & $1,83 \mathrm{a}$ & $3,1 \mathrm{a}$ & $2,1 \mathrm{a}$ \\
Café x pinus cuiabano & $75,45 \mathrm{a}$ & $12 \mathrm{a}$ & $1,57 \mathrm{a}$ & $2,9 \mathrm{a}$ & $2,5 \mathrm{a}$ \\
Café x cedro australiano & $72,64 \mathrm{a}$ & $7 \mathrm{~b}$ & $1,65 \mathrm{a}$ & $2,9 \mathrm{a}$ & $2,8 \mathrm{a}$ \\
\hline CV \% & $71,87 \mathrm{a}$ & $8 \mathrm{~b}$ & $1,35 \mathrm{a}$ & $2,7 \mathrm{a}$ & $2,4 \mathrm{a}$ \\
\hline
\end{tabular}

Médias seguidas pela mesma letra não diferem entre si pelo teste de Tukey a 5\%. Fonte: Adaptado de Rodrigues (2009).

Segundo Matiello et al. (2010), os cafeeiros em sistemas sombreados requerem menos fertilizantes, sobretudo os nitrogenados, para produzir uma mesma quantidade de grãos de café. Na Costa Rica, foi demonstrado esse fenômeno pela maior atividade da nitratoredutase sob menor luminosidade (café é planta C3, portanto o máximo de fotossíntese ocorre sob luz difusa). Além disso, o processo produtivo desde a floração até a maturação é mais lento e, desse modo, melhor atendido pela produção de reservas sob sombreamento da cultura.

Tatagiba et al. (2010), em experimento com mudas de café utilizando sombreamento artificial, observou que as plantas cresceram melhor a $22 \%$ e $50 \%$ de sombreamento, apresentando maior crescimento vegetativo em relação às mantidas a pleno sol e ao sombreamento de $88 \%$, propiciando a formação de mudas mais vigorosas, verificado principalmente pela matéria seca total das plantas (Figura 2).

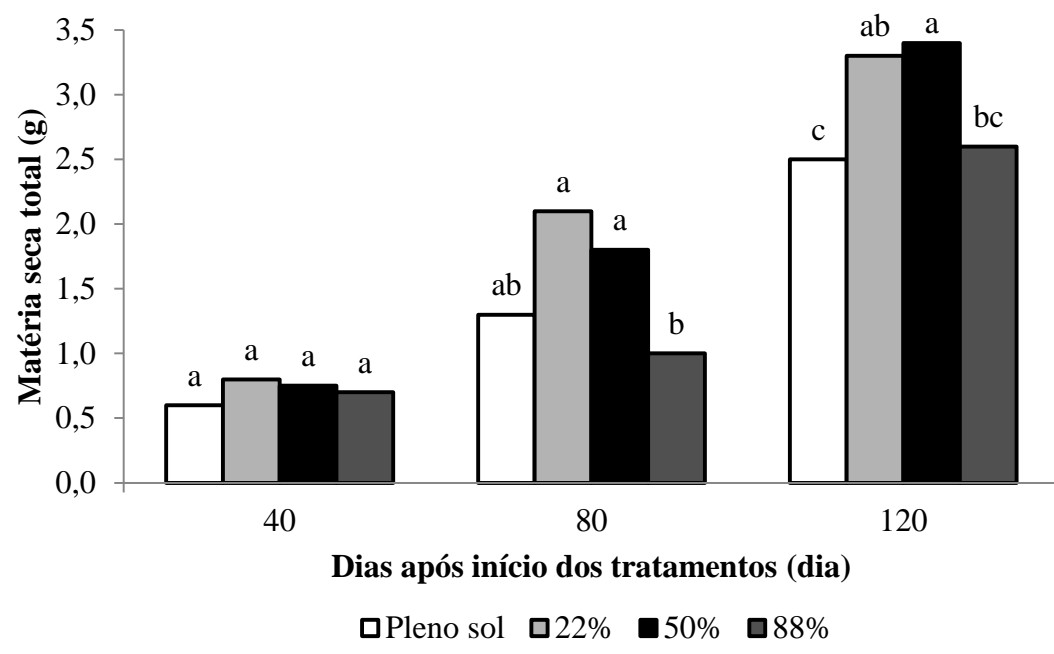

$\operatorname{rV}(\%)=$

Figura 2. Matéria seca total das mudas de café arábica, em diferentes épocas de crescimento, sob quatro níveis de sombreamento. Jerônimo Monteiro (ES). Médias seguidas de mesma letra nas colunas para cada época de avaliação, não diferenciam entre si a 5\% de probabilidade pelo teste Tukey. Fonte: Tatagiba et al. (2010). 
Pezzopane et al. (2007), trabalhando com cafezais a pleno sol e sombreados por banana prata-anã (Musa $\mathrm{AAB}$ ), constatou que no cultivo consorciado, especialmente nos cafeeiros mais próximos às bananeiras, houve diferenças significativas no crescimento vegetativo e no desenvolvimento fenológico em relação aos demais pontos avaliados, acarretando em uma menor produção por planta.

Lagemann e Heuveldop (1983) também relataram que uma maior densidade de sombreamento pode ter um efeito negativo na produção de café. Cafezais a pleno sol podem produzir mais do que lavouras sombreadas, ambas com o mesmo manejo (CHAMORRO et al., 1994). Todavia, em alguns experimentos realizados na Costa Rica, a produção das cultivares Bourbon e Caturra sombreadas por $E$. poeppigiana foi igual ou até mesmo maior que a produção obtida em cafezais a pleno sol, ambos, também, com o mesmo manejo (BEER et al., 1998).

Em altitudes menores, a produção de cafezais a pleno sol cai consideravelmente em virtude das altas temperaturas, enquanto que nas maiores altitudes ela cai em resposta às baixas temperaturas e, possivelmente, aos danos causados pelos ventos. Nesses ambientes fora das condições ideais para a cultura do café, espécies de sombreamento podem amenizar as condições extremas do microclima e proporcionar um aumento na produção em relação aos ambientes a pleno sol. Porém, o sombreamento em locais onde a altitude e o clima são ideais pode ocasionar diminuição da produção (BEER et al., 1998).

Resultados de pesquisas na América Central mostram que a porcentagem de cobertura da lavoura por árvores de sombra exerceu efeito significativo nas produções de café. A cobertura da lavoura entre 23 e $38 \%$ por árvores de sombra aumentou a produção de café e houve manutenção deste resultado até $48 \%$ de cobertura (Figura 3). Contudo, a produção pode diminuir a partir de $50 \%$ de cobertura da lavoura (SOTO-PINTO et al., 2000).

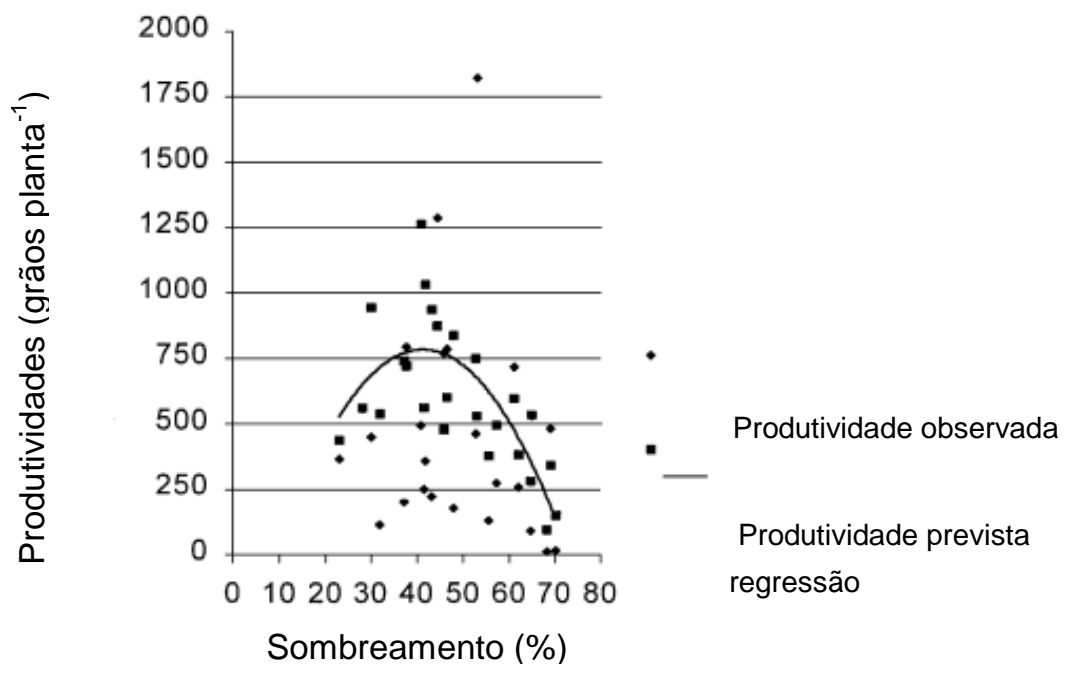

Figura 3. Efeito do sombreamento nas produtividades da cultura do café (densidade constante de 2.200 plantas ha ${ }^{-1}$ ). Chilón - Chiapas (México). Fonte: Soto-Pinto et al. (2000). 
Já Jaramillo-Botero et al. (2010), trabalhando com diferentes níveis de adubação e sombreamento em cafezais, observaram que não houve diminuição na produção das plantas sob sombra, comparadas com plantas submetidas a pleno sol durante o tempo das avaliações (Figura
4). Os autores constataram também resultados semelhantes entre as plantas com baixas doses de adubo e sob $48 \%$ de sombra e as expostas a pleno sol, com a dose recomendada de adubação.

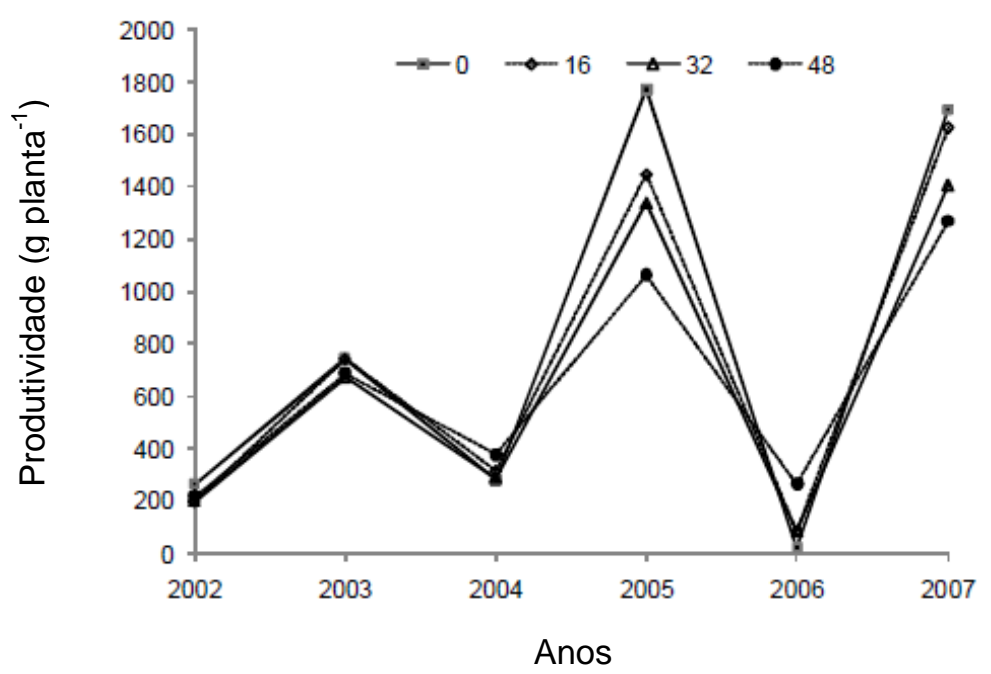

Figura 4. Média de produtividade por planta de café em cada nível de sombreamento $(0,16,32$ ou $48 \%$ da radiação fotossintéticamente ativa bloqueada) de 2002 a 2007. Viçosa (MG). Fonte: Jaramillo-Botero et al. (2010).

Apesar da hipótese de que o café sombreado apresentaria qualidade superior, Willey (1975 apud BEER et al., 1998) comenta que, embora a atenuação da luminosidade possa causar estiolamento e alterações na morfologia foliar, o sombreamento teria pouco efeito na morfologia e, consequentemente, na constituição química dos frutos. Assim sendo, o autor conclui que o sombreamento afeta somente a produção vegetativa, porém o efeito sobre a qualidade dos grãos de café seria pouco provável. Hernández (1995) relata diferenças não significativas entre o tamanho dos grãos produzidos em parcelas sombreadas e não sombreadas. Entretanto, durante dois anos consecutivos, o fator de conversão para grãos secos por unidade de peso de grãos verdes foi $0,6 \%$ maior para o café sombreado, o que representou um adicional de
$44 \mathrm{~kg} \mathrm{ha}^{-1}$ de café beneficiado em comparação ao sistema a pleno sol.

Em experimento na Costa Rica, com cafezais a pleno sol e sob $45 \%$ de sombra, Vaast et al. (2006) observaram decréscimo de $18 \%$ na produtividade do cafezal sombreado (Tabela 4). Contudo, o sombreamento afetou positivamente o tamanho do grão (Tabela 4) e sua composição, bem como a qualidade de bebida, devido ao prolongamento da fase de amadurecimento em um mês (Tabela 5). Ainda nesse trabalho, os teores de sacarose, ácido clorogênico e trigonelina foram maiores nos grãos do sistema a pleno sol (Tabela 5), o que explica o maior amargor e adstringência da bebida obtida a partir desses grãos (Tabela 6). 
Tabela 4. Efeito da intensidade da radiação fotossinteticamente ativa ( $45 \%$ de sombra ou a pleno sol) na produtividade de café, área abrangida pelos ramos, área foliar individual, relação folha/fruto e porcentagem de grãos graúdos. Heredia (Costa Rica).

\begin{tabular}{cccccccccccc}
\hline & \multicolumn{3}{c}{$\begin{array}{c}\text { Produtividade } \\
\text { (g planta-1 }\end{array}$} & \multicolumn{2}{c}{ Área ramo $\left(\mathrm{cm}^{2}\right)$} & \multicolumn{2}{c}{$\begin{array}{c}\text { Área foliar } \\
\left(\mathrm{cm}^{2}\right)\end{array}$} & $\begin{array}{c}\text { Folha/fruto }\left(\mathrm{cm}^{2}\right. \\
\text { fruto }\end{array}$ & \multicolumn{2}{c}{$\begin{array}{c}\text { \% grãos } \\
\text { graúdos }\end{array}$} \\
\cline { 2 - 13 } & 1999 & 2000 & 2001 & 1999 & 2000 & 1999 & 2000 & 1999 & 2000 & 1999 & 2000 \\
\hline Sombra & 2340 & 1770 & 2220 & 730 & 590 & 36 & 42 & 18 & 18 & 63,5 & 72,1 \\
Pleno sol & 2700 & 1880 & 3130 & 650 & 380 & 30 & 28 & 14 & 12 & 62,5 & 65,6 \\
\hline P & 0,03 & NS & 0,001 & 0,001 & 0,001 & 0,001 & 0,001 & 0,05 & 0,001 & NS & 0,001 \\
\hline
\end{tabular}

NS: não significativo ( $p>0,05)$. Fonte: Adaptado de Vaast et al. (2006).

Tabela 5. Efeito da intensidade da radiação fotossinteticamente ativa ( $45 \%$ de sombra ou a pleno sol) na composição bioquímica dos grãos de café $\left(\mathrm{g} \mathrm{kg}^{-1}\right.$ de peso de grão seco). Heredia (Costa Rica).

\begin{tabular}{ccccccccccc}
\hline & \multicolumn{2}{c}{ Cafeína } & \multicolumn{2}{c}{ Gorduras } & \multicolumn{2}{c}{ Sacarose } & Ác. clorogênico & \multicolumn{2}{c}{ Trigonelina } \\
\cline { 2 - 11 } & 1999 & 2000 & 1999 & 2000 & 1999 & 2000 & 1999 & 2000 & 1999 & 2000 \\
\hline Sombreado & 14,8 & 14,1 & 131 & 117 & 82 & 77,3 & 76,2 & 82,1 & 9,9 & 9,7 \\
Pleno sol & 14,2 & 13,6 & 122 & 115 & 84 & 78,4 & 77,1 & 82,6 & 10,7 & 10,1 \\
\hline P & 0,001 & 0,001 & 0,001 & 0,05 & 0,001 & NS & 0,001 & NS & 0,001 & 0,001 \\
\hline
\end{tabular}

NS: não significativo ( $p>0,05)$. Fonte: Adaptado de Vaast et al. (2006).

Tabela 6. Efeito da intensidade da radiação fotossinteticamente ativa ( $45 \%$ de sombra ou a pleno sol) nas características de bebida. Heredia (Costa Rica).

\begin{tabular}{ccccccccccc}
\hline & \multicolumn{3}{c}{ Acidez $^{\mathrm{a}}$} & \multicolumn{2}{c}{ Amargor $^{\mathrm{a}}$} & \multicolumn{2}{c}{ Adstringência $^{\mathrm{a}}$} & \multicolumn{2}{c}{ Corpo $^{\mathrm{a}}$} & \multicolumn{3}{c}{ Preferência $^{\mathrm{b}}$} \\
\cline { 2 - 11 } & 1999 & 2000 & 1999 & 2000 & 1999 & 2000 & 1999 & 2000 & 1999 & 2000 \\
\hline Sombreado & 2,27 & 2,45 & 2,65 & 2,65 & 1,68 & 0,35 & 2,78 & 2,50 & 2,57 & 2,80 \\
Pleno sol & 1,67 & 2,21 & 2,95 & 2,88 & 1,86 & 0,41 & 2,91 & 2,67 & 2,29 & 2,58 \\
\hline P & 0,001 & 0,04 & 0,002 & 0,01 & 0,02 & NS & 0,05 & 0,05 & 0,01 & 0,02 \\
\hline
\end{tabular}

${ }^{a}$ As pontuações para acidez, amargor, adstringência e corpo foram baseados em uma escala de $0-5$, onde $0=$ nulo, $1=$ muito leve, $2=$ leve, 3 = regular, 4 = forte e $5=$ muito forte. ${ }^{b}$ Preferência geral foi baseada em uma de escala de $0-4$, onde $0=$ não é bom para beber, 1 = ruim, 2 = regular, 3 = bom e $4=$ muito bom. Cada valor é a pontuação média de dez juízes e três sessões de prova. NS: não significativo ( $\mathrm{P}>0,05)$. Fonte: Adaptado de Vaast et al. (2006).

A produção de madeira pelas espécies de sombreamento reduz os custos de manejo (CALVO; PLATEN, 1996) e gera renda em períodos de preços baixos da cultura do café. Além da madeira, podem-se utilizar espécies de sombreamento que forneçam outros produtos, como lenha, frutas (banana, coco), nozes (macadâmia), entre outros (PEZZOPANE et al., 2010).

\section{3 - CONSIDERAÇÕES FINAIS}

O cultivo de café sombreado torna-se uma alternativa interessante e viável, não somente pelo seu centro de origem ser em florestas tropicais africanas e pela possibilidade de produção de um café com melhor qualidade, mas também pelo incremento de renda que as espécies de sombreamento podem proporcionar ao produtor através de outros produtos de interesse econômico, como madeira, frutos, nozes, entre outros. Outro aspecto importante diz respeito à venda de créditos de carbono, cada 
vez mais valorizada no mercado internacional. Contudo, deve-se atentar à escolha da espécie de sombreamento adequada, ao nível de sombreamento, o solo, a altitude e o clima, entre outros fatores, sempre realizando um manejo apropriado tanto da cultura consorciada quanto do cafezal, para que ambos possam produzir satisfatoriamente.

\section{4 - REFERÊNCIAS BIBLIGRÁFICAS}

AGRIOS, G.N. Plant Pathology. Orlando: Academic Press, 1982. 633p.

AMARAL, I.C. Viabilidade de plantio de café na Zona da Mata mineira. Revista de Política Agrícola, v. 20, n. 4, p. 84-97, 2011.

ARAYA, M. Distribucion y niveles poblacionales de Meloidogyne spp. y Pratylenchus spp. en ocho cantones productores de café en Costa Rica. Agronomia Costarricense, v. 18, n. 2, p. 183187, 1994.

BABBAR, L.I.; ZAK, D.R. Nitrogen cycling in coffee agroecosystems: net nitrogen mineralization and nitrification in the presence and absence of shade trees. Agricultural Ecosystems \& Environmental, v. 48, n. 2, p. 107-113, 1994. http://dx.doi.org/10.1016/01678809(94)90081-7

BABBAR, L.I.; ZAK, D.R. Nitrogen loss from coffee agroecosystems in Costa Rica. Leaching and denitrification in the presence and absence of shade trees. Journal of Environmental Quality, v. 24, n. 2, p. 227-233, 1995. http://dx.doi.org/10.2134/jeq1995.0047242500240 0020003x

BARRADAS, V.L.; FANJUL, L. Microclimatic characterization of shaded and open-grown coffee (Coffea arabica L.) plantations in Mexico. Agriculture and Forestry Meteorology, v. 38, n. 1, p. 101-112, 1986.

BEER, J.W. Litter production and nutrient cycling in coffee (Coffea arabica) or cacao (Theobroma cacao) plantations with shade trees. Agroforestry Systems, v. 7, n. 2, p. 103-114, 1988. http://dx.doi.org/10.1007/BF00046846

J. BEER, J.; MUSCHLER, R.; KASS, D.; SOMARRIBA, E. Shade management in coffee and cacao plantations. Agroforestry Systems, v. 38, n. 1-3, p. 139-164, 1998. http://dx.doi.org/10.1007/978-94-015-9008-2_6
BERGAMIN, J. As chuvas e a broca do café. Boletim da Superintendência dos Serviços do café, v. 41, n. 232, p. 282-283, 1946.

BOYCE, J.K.; FERNÁNDEZ, G.A.; FURST, E.; SEGURA, B.O. Café y desarrollo sostenible: del cultivo agroquímico a la producción orgánica en Costa Rica. San José: Heredia, 1994. 248 p.

CALVO, G.; von PLATEN, H. Cacao-laurelplátano. Costos y beneficios financieros. Informe Técnico n.264. Turrialba: CATIE, 1996. $54 \mathrm{p}$.

CAMPANHA, M.M. et al. Incidência de pragas e doenças em cafeeiros cultivados em sistema agroflorestal e em cultivo solteiro. Revista Ceres, v. 51, n. 295 , p. 391-396, 2004

CANNELL, M.G.R. Crop physiological aspects of coffee bean yield: a review. Journal of Coffee Research, v. 5, n. 1-2, p. 7-20, 1975.

CHAMORRO, G.; GALLO, A.; LOPEZ, R. Evaluación económica del sistema agroforestal café asociado con nogal. Cenicafé, v. 45, n. 4, p. 164-170, 1994.

CUENCA, G.; ARANGUREN, J.; HERRERA, R. Root growth and litter decomposition in a coffee plantation under shade trees. Plant and Soil, v.71, p.477-486, 1983.

DAMATTA, F.M. Ecophysiological constraints on the production of shaded and unshaded coffee: a review. Field Crops Research v. 86, n. 2-3, p. 99-114,2004

http://dx.doi.org/10.1016/j.fcr.2003.09.001

DIXON, R.K. Agroforestry systems: sources or sinks of greenhouse gases. Agroforestry Systems, v. 31, n. 2, p. 99-116, 1995. http://dx.doi.org/10.1007/BF00711719

ESKES, A.B. The effect of light intensity on incomplete resistance of coffee to Hemileia vastatrix. Netherlands Journal of Plant Pathology, v. 88, n. 5, p. 191-202, 1982. http://dx.doi.org/10.1007/BF02140882

FASSBENDER, H.W. Nutrient cycling in agroforestry systems of coffee (Coffea arabica) with shade trees in the Central Experiment of CATIE. In: BEER, J.; FASSBENDER, H.; HEUVELDOP, J. (Eds.). Advances in Agroforestry Research. Turrialba: CATIE, 1987. cap. 2, p. 155-165.

FAZUOLI, L.C.; THOMAZIELLO, R.A.; CAMARGO, M.B.P. Aquecimento global, mudanças climáticas e a cafeicultura paulista. $\mathbf{O}$ Agronômico, v. 59, n. 1, p. 19-20, 2007. 
FERNANDES, D.R. Manejo do Cafezal. In: RENA, A.B.; MALAVOLTA, E.; ROCHA, M.; YAMADA, T. (Eds.). Cultura do Cafeeiro. Piracicaba: Potafós, 1986. cap. 36, p. 275- 301.

HERNÁNDEZ, O.R. Rendimiento y análisis financiero del sistema agroforestal café (Coffea arabica cv Caturra) con poró (Erythrina poeppigiana) bajo diferentes densidades de laurel (Cordia alliodora). 1995. 60 p. Dissertação (Mestrado em Fitotecnia) CATIE, Turrialba, 1995.

JARAMILLO, A.; VALENCIA, G. Los elementos climáticos y el desarrollo de Coffea arábica L. en Chinchina. Cenicafe, v. 31 , n. 4, p. 127-143, 1980.

JARAMILLO-BOTERO, C.; SANTOS, R.H.S.; MARTINEZ, H.E.P.; CECON, P.R.; FARDIN, M.P. Production and vegetative growth of coffee trees under fertilization and shade levels. Scientia Agricola, v. 67, n. 6, p. 639-645, 2010.

KUMAR, D.; TIESZEN, L.L. Photosynthesis in Coffea arabica L. I. Effects of light and temperature. Experimental Agriculture, v. 16, n. 1, p. 13-19, 1980.

KURSTEN, E.; BURSCHEL, P. $\mathrm{CO}_{2}$ mitigation by agroforestry. Water, Air and Soil Pollution, v. 70, n. 1-4, p. 533-544, 1993. http://dx.doi.org/10.1007/BF01105020

LAGEMANN, J.; HEUVELDOP, J. Characterization and evaluation of agroforestry systems, the case of Acosta - Puriscal, Costa Rica. Agroforestry Systems, v. 1, n. 2, p. 101115, 1983. http://dx.doi.org/10.1007/BF00596352

LEON, R.A. Determinación de la hidroerosión laminar, utilizando varillas metalicas asociadas a parcelas de escorrentia. 1990. 174 p. Dissertação (Mestrado em Fitotecnia) - CATIE, Turrialba, 1990.

LINDBLAD, P.; RUSSO, R. $\mathrm{C}_{2} \mathrm{H}_{2}$ reduction by Erythrina poeppigiana in a Costa Rican coffee plantation. Agroforestry Systems, v. 4, n. 1, p. 33-37, 1986.

LOCK, C.G.W. Coffee: its culture and commerce in all countries. Londres: E \& FN Spon, 1888. 274 p.

MAESTRI M, BARROS RS. Coffee. In: Alvim PT, Kozlowski TT (eds), Ecophysiology of Tropical Crops, 1977, p. 249-278. Academic Press, London.

MATIELlO, J.B. Sistemas de Produção na Cafeicultura Moderna, Tecnologias de plantio adensado, renque mecanizado, arborização e recuperação de cafezais. Rio de Janeiro: MM Produções Gráficas, 1995. 102 p.

MATIELLO, J.B.; SANTINATO, R.; GARCIA, A.W.R.; ALMEIDA, S.R.A.; FERNANDES, D.R. Cultura de café no Brasil: novo manual de recomendações. Rio de Janeiro: MAPA/PROCAFÉ, 2010. 542 p.

MOREIRA, C.F.; FERNANDES, E.A.D.; TAGLIAFERRO, F.S. Discriminação de café orgânico produzido sob sombra e a pleno sol pela composição química elementar. In: CONGRESSO BRASILEIRO DE METROLOGIA, 3, 2003, Recife. Artigos... São Paulo, SP: O2 Estúdio Web / Metrologia \& Instrumentação, 2003. v. 3, p. 1-5.

MUSCHLER, R.G. Efectos de diferentes niveles de sombra de Erythrina poeppigiana sobre Coffea arabica vars. Caturra y Catimor. In: II SEMANA CIENTÍFICA DEL CENTRO AGRONÓMICO TROPICAL DE INVESTIGACIÓN Y ENSEÑANZA， 2, 1995, Turrialba. Artigos... Turrialba, Costa Rica: CATIE, 1995. v. 2, p.158160.

MUSCHLER, R.G. Shade or sun for ecologically sustainable coffee production: a summary of environmental key factors. In: III SEMANA CIENTÍFICA DEL CENTRO AGRONÓMICO TROPICAL DE INVESTIGACIÓN Y ENSEÑANZA, 3, 1997, Turrialba. Artigos... Turrialba, Costa Rica: CATIE, 1997. v. 3, p.109112.

NATARAJ, T.; SUBRAMANIAN, S. Effect of shade and exposure on the incidence of rowneyespot of coffee. Indian Coffee, v. 39, n. 2, p. 179180, jun. 1975.

NUNES, M.A.; RAMALHO, J.D.C.; DIAS, M.A. Effect of nitrogen supply on the photosynthetic performance of leaves from coffee plants exposed to bright light. Journal of Experimental Botany, v. $44, \quad$ n. $5, \quad$ p. 893-899, 1993. http://dx.doi.org/10.1093/jxb/44.5.893

OFICAFE. Manual de recomendaciones para cultivar café. San José: Oficina de café Ministerio de Agricultura y Ganaderia, 1978. 245 p.

PERFECTO, I.; RICE, R.A.; GREENBERG, R.; Van Der VOORT, M.E. Shade coffee: a disappearing refuge for biodiversity. BioScience, v. $46, \quad$ n. $8, \quad$ p. $598-608,1996$. http://dx.doi.org/10.2307/1312989

Pezzopane, J.R.M.; Marsetti, M.M.S.; Souza, J.M.; Pezzopane, J.E.M. Condições microclimáticas em cultivo de café conilon a pleno 
sol e arborizado com nogueira macadâmia. Ciência Rural, v. 40, n. 6, p. 1257-1263, 2010. http://dx.doi.org/10.1590/S0103-

84782010005000098

PEZZOPANE, J.R.M.; PEDRO JÚNIOR, M.J.; GALLO, P.B.; CARMARGO, M.B.P.; FAZUOLI, L.C. Avaliações fenológicas e agronômicas em café arábica cultivado a pleno sol e consorciado com banana prata anã. Bragantia,, v. 66, n. 4, p. 527-533, 2007. http://dx.doi.org/10.1590/S000687052007000400021

RODRIGUES, V.G.S. Avaliação do desenvolvimento vegetativo de cafeeiros arborizados e a pleno sol. Porto Velho: Embrapa Rondônia, 2009. 4 p. (Circular Técnica no 112).

RODRIGUES, V.G.S. et al. Arborização em Lavouras de Café - Experiências de Agricultores em Rondônia-Brasil. In: II SIMPÓSIO DE PESQUISA DOS CAFÉS DO BRASIL, 2, 2001, Vitória. Anais Eletrônicos... Vitória, ES: Embrapa Café, 2001. v. 2, p. 1612-1617.

ROJAS CUBERO, R. Modelo de costos de producción de café. San José: Instituto del Café de Costa Rica, 1996. 163 p.

ROSKOWSKI, J.P.; van KESSEL, C. Annual seasonal and daily variation in nitrogen fixing activity by Inga jinicuil, a tropical leguminous tree. Oikos, v. 44, n. 2, p. 306-312, 1985.

SILVA, N.T.M.H.; TISDELL, C.A.; BYRNE, P.N. Evaluating techniques for weed control in coffee in Papua New Guinea. International Tree Crops Journal, v. 6, n. 1, p. 31-49, 1990.

SOTO-PINTO, L. et al. Shade effect on coffee production at the northern Tzeltal zone of the state of Chiapas, Mexico. Agriculture, Ecosystems and Environment, v. 80, n. 1-2, p. 61-69, 2000. http://dx.doi.org/10.1016/S0167$8809(00) 00134-1$

TATAGIBA, S.D.; PEZZOPANE, J.E.M.; REIS, E.F. Crescimento vegetativo de mudas de café arábica (Coffea arabica L.) submetidas a diferentes níveis de sombreamento. Coffee Science, v. 5, n. 3, p. 251-261, 2010.

TEODORO, A.; KLEIN, A.M.; REIS, P.R.; TSCHARNTKE, T. Agroforestry management affects coffee pests contingent on season and developmental stage. Agricultural and Forest Entomology, v. 11, n. 3, p. 295-300, 2009. http://dx.doi.org/10.1111/j.1461-

9563.2008.00417.x
VAAST, P.; BERTRAND, B.; PERRIOT, J-J.; GUYOT, B.; GÉNARD, M. Fruit thinning and shade improve bean characteristics and beverage quality of coffee (Coffea arabica L.) under optimal conditions. Journal of the Science of Food and Agriculture, v. 86, n. 2, p. 197-204, http://dx.doi.org/10.1002/jsfa.2338

VAAST, P. et al. Shade: A key factor for coffee sustainability and quality. In: ASIC CONFERENCE, 2004, Bangalore. Resumos... Bangalore, India: Association Scientifique Internationale du Café, 2004. CD-ROOM.

WRIGLEY, G. Coffee. Nova York: Longman Scientific Technical and John Wiley \& Sons, 1988. $639 \mathrm{p}$.

ZAMORA, G.; SOTO, B. Arboles usados como sombra para café y cacao. Revista Cafetalera, v. 159, n. 4, p. 27-32, 1976. 